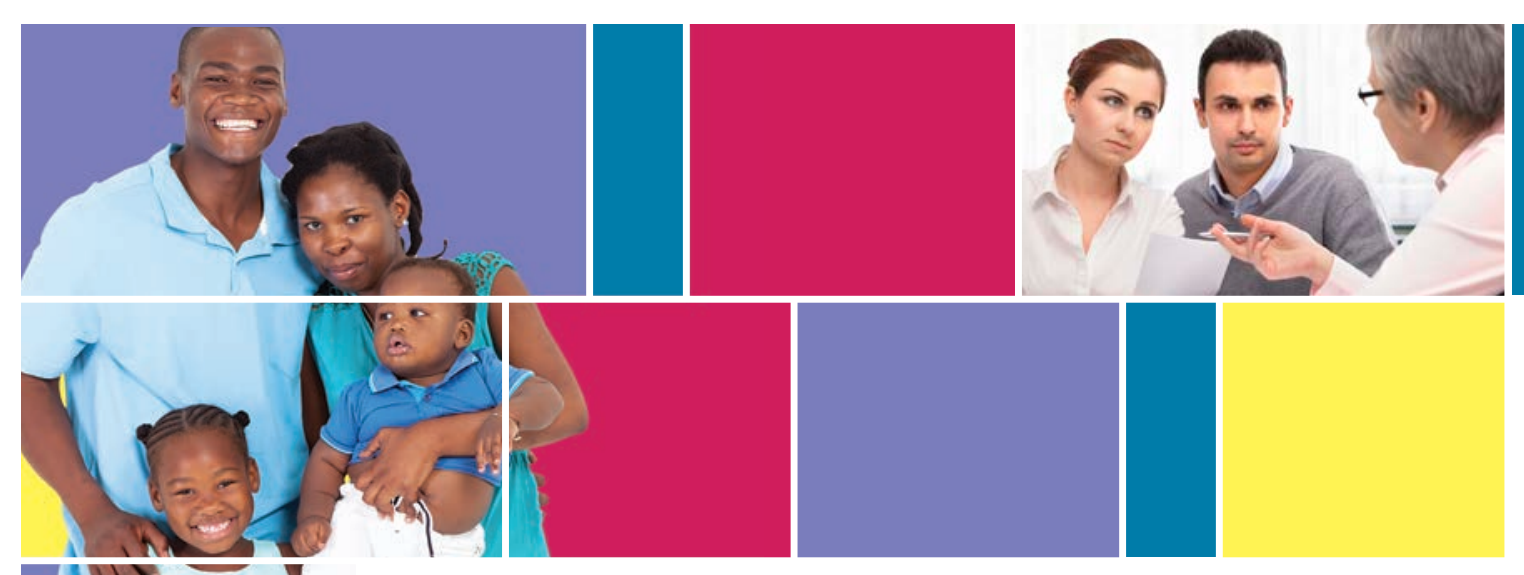

FACTSHEET

April 2019

\title{
Long-Term Consequences of Child Abuse and Neglect
}

Aside from the immediate physical injuries children can experience through maltreatment, a child's reactions to abuse or neglect can have lifelong and even intergenerational impacts. Childhood maltreatment can be linked to later physical, psychological, and behavioral consequences as well as costs to society as a whole. These consequences may be independent of each other, but they also may be interrelated. For example, abuse or neglect may stunt physical development of the child's brain and lead to psychological problems, such as low selfesteem, which could later lead to high-risk behaviors, such as substance use. The outcomes for each child may vary widely and are affected by a combination of factors, including the child's age and developmental status when the maltreatment occurred; the type, frequency, duration, and severity of the maltreatment; and the relationship between the child and the perpetrator. Additionally, children who experience maltreatment often are affected by other adverse experiences (e.g., parental substance use, domestic violence, poverty), which can make it difficult to separate the unique effects of maltreatment (Rosen, Handley, Cicchetti, \& Rogosch, 2018).

\section{WHAT'S INSIDE}

Physical health consequences

Psychological consequences

Behavioral consequences

Societal

consequences

Federal research on adverse childhood experiences

Preventing and reducing the longterm consequences of maltreatment

Conclusion

References 
This factsheet explains the long-term physical, psychological, behavioral, and societal consequences of child abuse and neglect and provides an overview of adverse childhood experiences (ACEs). It also discusses the importance of prevention and intervention efforts and promoting protective relationships and environments.

For more information on abuse and neglect, read Child Welfare Information Gateway's What Is Child Abuse and Neglect? Recognizing the Signs and Symptoms, which is available at https://www. childwelfare.gov/pubs/factsheets/whatiscan, and Definitions of Child Abuse and Neglect, which is available at https://www.childwelfare.gov/topics/ systemwide/laws-policies/statutes/define/.

\section{Physical Health Consequences}

Some long-term physical effects of abuse or neglect may occur immediately (e.g., brain damage caused by head trauma), but others can take months or years to emerge or be detectable. There is a straightforward link between physical abuse and physical health, but it is also important to recognize that maltreatment of any type can cause long-term physical consequences.

Childhood maltreatment has been linked to higher risk for a wide range of long-term and/or future health problems, including - but not limited to-the following (Widom, Czaja, Bentley, \& Johnson, 2012; Monnat \& Chandler, 2015; Afifi et al., 2016):

- Diabetes

- Lung disease

- Malnutrition

- Vision problems

- Functional limitations (i.e., being limited in activities)

- Heart attack

- Arthritis

- Back problems

- High blood pressure

- Brain damage
- Migraine headaches

- Chronic bronchitis/emphysema/chronic obstructive pulmonary disease

- Cancer

- Stroke

- Bowel disease

- Chronic fatigue syndrome

Child abuse and neglect also has been associated with certain regions of the brain failing to form, function, or grow properly. For example, a history of maltreatment may be correlated with reduced volume in overall brain size and may affect the size and/or functioning of the following brain regions (Bick \& Nelson, 2016):

- The amygdala, which is key to processing emotions

- The hippocampus, which is central to learning and memory

- The orbitofrontal cortex, which is responsible for reinforcement-based decision-making and emotion regulation

- The cerebellum, which helps coordinate motor behavior and executive functioning

- The corpus callosum, which is responsible for left brain/right brain communication and other processes (e.g., arousal, emotion, higher cognitive abilities)

Fortunately, however, there is promising evidence that children's brains may be able to recover with the help of appropriate interventions (Bick \& Nelson, 2016). For additional information about these impacts, refer to Information Gateway's Understanding the Effects of Maltreatment on Brain Development (https://www. childwelfare.gov/pubs/issue-briefs/brain-development/).

Additionally, the type of maltreatment a child experiences can increase the risk for specific physical health conditions. For example, one study found that children who experienced neglect were at increased risk for diabetes, poorer lung functioning, and vision and oral health problems. Children who had been physically abused were at higher risk for diabetes and malnutrition. Children who were victims of sexual abuse were more likely to contract hepatitis C and HIV (Widom et al., 2012).

This material may be freely reproduced and distributed. However, when doing so, please credit Child Welfare Information Gateway. 


\section{Epigenetics}

Epigenetics refers to changes in how an individual's genes are expressed and used, which may be temporary or permanent (National Scientific Council on the Developing Child, 2010). These changes can even be passed on to the person's children. An epigenetic change can be caused by life experiences, such as child maltreatment or substance exposure. For example, one study found that children who had been maltreated exhibited changes in genes associated with various physical and psychological disorders, such as cancer, cardiovascular disease, immune disorders, schizophrenia, bipolar disorder, and depression (Cicchetti et al., 2016).

\section{Psychological Consequences}

Child abuse and neglect can cause a variety of psychological problems. Maltreatment can cause victims to feel isolation, fear, and distrust, which can translate into lifelong psychological consequences that can manifest as educational difficulties, low self-esteem, depression, and trouble forming and maintaining relationships. Researchers have identified links between child abuse and neglect and the following psychological outcomes.

\section{Diminished executive functioning and cognitive skills.}

Disrupted brain development as a result of maltreatment can cause impairments to the brain's executive functions: working memory, self-control, and cognitive flexibility (i.e., the ability to look at things and situations from different perspectives) (Kavanaugh, Dupont-Frechette, Jerskey, \& Holler, 2016). Children who were maltreated also are at risk for other cognitive problems, including difficulties learning and paying attention (Bick \& Nelson, 2016).
Poor mental and emotional health. Experiencing childhood maltreatment is a risk factor for depression, anxiety, and other psychiatric disorders throughout adulthood. Studies have found that adults with a history of ACEs had a higher prevalence of suicide attempts then those who did not (Choi, DiNitto, Marti, \& Segal, 2017; Fuller-Thomson, Baird, Dhrodia, \& Brennenstuhl, 2016). (For additional information about ACEs, see the Federal Research on Adverse Childhood Experiences section later in this factsheet.) Further, adults with major depression who experienced abuse as children had poorer response outcomes to antidepressant treatment, especially if the maltreatment occurred when they were aged 7 or younger (Williams, Debattista, Duchemin, Schatzberg, \& Nemeroff, 2016).

Attachment and social difficulties. Infants in foster care who have experienced maltreatment followed by disruptions in early caregiving can develop attachment disorders. Attachment disorders can negatively affect a child's ability to form positive peer, social, and romantic relationships later in life (Doyle \& Cicchetti, 2017).

Additionally, children who experience abuse or neglect are more likely to develop antisocial traits as they grow up, which can lead to criminal behavior in adulthood (U.S. Department of Justice, Office of Justice Programs, National Institute of Justice, 2017).

Posttraumatic stress. Children who experienced abuse or neglect can develop posttraumatic stress disorder (PTSD), which is characterized by symptoms such as persistent re-experiencing of the traumatic events related to the abuse; avoiding people, places, and events that are associated with their maltreatment; feeling fear, horror, anger, guilt, or shame; startling easily; and exhibiting hypervigilance, irritability, or other changes in mood (Sege et al., 2017). PTSD in children can lead to depression, suicidal behavior, substance use, and oppositional or defiant behaviors well into adulthood, which can affect their ability to succeed in school, and create and nurture important relationships. 


\section{Toxic Stress}

Strong, frequent, or prolonged activation of a person's stress response system, often referred to as toxic stress, can have long-lasting damaging effects on an individual's health, behavior, and ability to learn (National Scientific Council on the Developing Child, 2014). Toxic stress can be caused by experiencing ACEs, including child maltreatment. It can change an individual's brain architecture, which can cause the person's stress response system to be triggered more frequently and for longer periods of time and place him or her at an increased risk for a variety of physical and mental health problems, including cardiovascular disease, depression, and anxiety (National Scientific Council on the Developing Child, 2014). Trauma-informed approaches, however, can help improve outcomes for individuals affected by toxic stress, and there is evidence that social and emotional support (e.g., consistent parenting practices, community supports) can alleviate its effects (U.S. Department of Health and Human Services [HHS], Administration for Children and Families [ACF], 2017).

For more information about toxic stress, visit the Center on the Developing Child at Harvard University at https://developingchild.harvard.edu/ guide/a-guide-to-toxic-stress/.

\section{Behavioral Consequences}

Victims of child abuse and neglect often exhibit behavioral difficulties even after the maltreatment ends. The following are examples of how maltreatment can affect individuals' behaviors as adolescents and adults.

Unhealthy sexual practices. Studies suggest that abused or neglected children are more likely to engage in sexual risk-taking as they reach adolescence, including a higher number of sexual partners, earlier initiation of sexual behavior, and transactional sex (i.e., sex exchanged for money, gifts, or other material support) (Thompson et al., 2017), which increases their chances of contracting a sexually transmitted disease.

\section{Juvenile delinquency leading to adult criminality.}

Several studies have documented the correlation between child maltreatment and future juvenile delinquency and criminal activities (Herrenkohl, Jung, Lee, \& Kim, 2017). According to research funded by the National Institute of Justice within the U.S. Department of Justice, Office of Justice Programs, children who experience maltreatment in the form of physical and emotional abuse are more likely to develop antisocial behaviors and form relationships with other antisocial people (U.S. Department of Justice, Office of Justice Programs, National Institute of Justice, 2017).

Furthermore, there is a difference between girls and boys in the way child maltreatment influences delinquent behavior. In the study, girls tended to express internalizing behaviors (e.g., depression, social withdrawal, anxiety), while boys tended to express externalizing behaviors (e.g., bullying, aggression, hostility) leading up to adult criminal behavior (Herrenkohl et al., 2017).

Alcohol and other drug use. Adults who had been maltreated as children are at a significantly higher risk of substance use disorders than adults who have not been maltreated (LeTendre \& Reed, 2017; (Choi, DiNitto, Marti, \& Choi, 2017).

Future perpetration of maltreatment. Although most children who have experienced abuse and neglect do not go on to abuse or neglect their own children, research suggests they are more likely to do so compared to children who were not maltreated (Yang, Font, Ketchum, \& Kim, 2018). This cycle of maltreatment can be a result of children learning early on that physical abuse or neglect is an appropriate way to parent (Child Welfare Information Gateway, 2018). To learn more, read Information Gateway's Intergenerational Patterns of Child Maltreatment: What the Evidence Shows, available at https://www.childwelfare. gov/pubs/issue-briefs/intergenerational/. 


\section{Societal Consequences}

Although the physical, psychological, and behavioral consequences of child abuse and neglect weigh heavily on the shoulders of the children who experience it, the impact of maltreatment does not end there. Society pays a price for child abuse and neglect in both direct costs (e.g., hospitalizations, foster care payments) and indirect costs (e.g., long-term care, lost productivity at school, juvenile and criminal justice systems costs).

A study by researchers from the Centers for Disease Control and Prevention (CDC) developed estimates using 2015 data for the cost of child maltreatment in the United States. For nonfatal incidents of child maltreatment, the researchers estimated a lifetime cost of $\$ 831,000$ per child, and for fatal incidents of child maltreatment, it estimated a lifetime cost of $\$ 16.6$ million per child (Peterson, Florence, \& Klevens, 2018). It appraised the annual cost of nonfatal child maltreatment in the United States to be $\$ 428$ billion (based on the number of substantiated cases of nonfatal maltreatment) or $\$ 2$ trillion (based on the number of investigated instances of nonfatal maltreatment). The costs in this study include both tangible costs (e.g., child welfare, health care, juvenile justice) and intangible costs (e.g., pain, suffering, grief).

For more information on the economic and societal costs of child abuse and neglect, see the following Information Gateway webpages: Cost-of-Injury Analysis (https://www. childwelfare.gov/topics/preventing/developing/economic/ cost-injury/) and Social and Economic Consequences of Child Abuse and Neglect (https://www.childwelfare.gov/ topics/can/impact/consequences/).

\section{Federal Research on Adverse Childhood Experiences}

ACEs refers to a group of traumatic experiences in childhood, including maltreatment, that can cause toxic stress and affect an individual's physical, psychological, and behavioral well-being.' (See figure 1 for a representation of how ACEs affect an individual throughout his or her life.) Between 1995 and 1997, the CDC, in collaboration with Kaiser Permanente's Health Appraisal Clinic, conducted the landmark ACEs study, which examined the correlation between childhood trauma and adult health and well-being outcomes. Research that explores ACEs and how to respond to them is still ongoing. Findings from a subsequent study showed that nearly half of children in the United States experienced at least one ACE and that about 1 in 10 had experienced three or more ACEs (Sacks \& Murphey, 2018). For more information about the study, visit https://www. cdc.gov/violenceprevention/acestudy/.

Figure 1. ACEs Pyramid

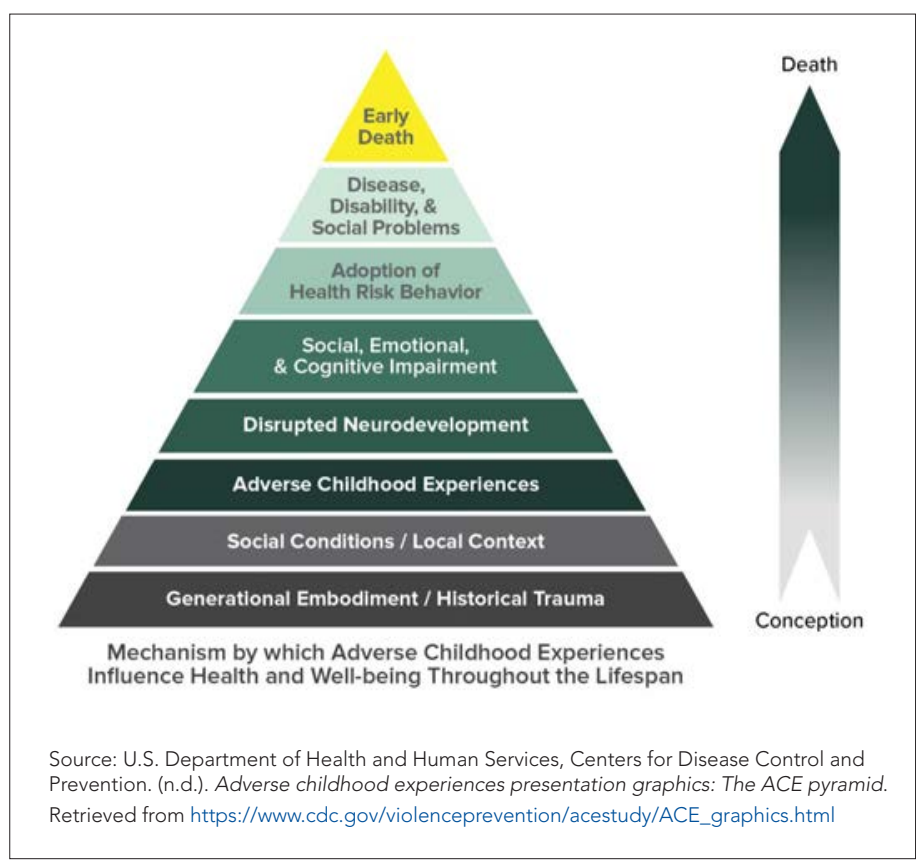

The following are the 10 ACEs generally studied: physical abuse, sexual abuse, emotional abuse, physical neglect, emotional neglect, intimate partner violence within the household, substance misuse within the household, mental illness within the household, parental separation or divorce, and incarcerated household member.

This material may be freely reproduced and distributed. However, when doing so, please credit Child Welfare Information Gateway. 
Two additional Federal research initiatives regarding ACES are the National Survey of Child and Adolescent Well-Being (NSCAW) and the Behavioral Risk Factor Surveillance System (BRFSS):

- NSCAW is a project of the Administration on Children, Youth and Families within HHS/ACF. It seeks to describe the child welfare system and the experiences of children and families who come into contact with it. Survey data are collected firsthand from children, parents, other caregivers, caseworkers, and teachers as well as administrative records. As a longitudinal study, NSCAW follows the life course of these children to gather data about service receipt, child well-being, and other outcomes. This information will provide a clearer understanding of the life outcomes of children and families involved with child welfare. For more information, visit https://www.acf.hhs.gov/opre/ research/project/ national-survey-of-child-and-adolescent-well-beingnscaw.

- BRFSS is an annual national telephone survey that collects State data on U.S. residents ages 18 years or older regarding their health-related risk behaviors, chronic health conditions, and use of preventative services. BRFSS consists of a core module as well as optional modules that States can incorporate. In addition, many States develop their own questions to meet their needs. The HHS CDC developed an optional ACEs module that was available from 2009 to 2011. Since 2011, many States have continued to add the ACEs module to their surveys as State-added questions. For more information, visit the CDC website at https://www.cdc.gov/brfss/index.html.

Promising evidence-based strategies have emerged to help combat the effects of ACEs on future outcomes and well-being. These include enlisting communities to promote stable, safe, and nurturing environments for children; using data to inform programs and services for preventing child maltreatment; and implementing community efforts that support parenting programs and positive parenting behaviors (HHS, CDC, National Center for Injury Prevention and Control, Division of Violence Prevention, 2014).
For more information on ACEs, including related research, refer to the following:

- ACEs Connection [website]: https://www.acesconnection.com/

- ACEs Resource Packet: Adverse Childhood Experiences (ACEs) Basics: http://childhealthdata.org/docs/defaultsource/cahmi/aces-resource-packet_all-pages_12_0616112336f3c0266255aab2ff00001023b1.pdf?sfvrsn=2

- Adverse Childhood Experiences [webpage] https://www.cdc.gov/violenceprevention/acestudy/ index.html

- Childhood Trauma and Positive Health [webpage] http://www.cahmi.org/projects/ adverse-childhood-experiences-aces/

- A National and Across-State Profile on Adverse Childhood Experiences Among U.S. Children and Possibilities to Heal and Thrive http://www.cahmi.org/wp-content/uploads/2018/05/ aces_brief_final.pdf

- The Prevalence of Adverse Childhood Experiences, Nationally, by State, and by Race or Ethnicity https://www.childtrends.org/publications/ prevalence-adverse-childhood-experiences-nationallystate-race-ethnicity

\section{Preventing and Reducing the Long- Term Consequences of Maltreatment}

By reducing the incidence of child abuse and neglect through primary prevention approaches and providing comprehensive, trauma-informed care when it does occur, communities can limit its long-term consequences. In trauma-informed care, service professionals acknowledge a child's history of trauma and how that trauma can have an impact on the symptoms-or consequences-being experienced by the child. For more information on trauma-informed practice, visit Information Gateway at https://www.childwelfare.gov/topics/responding/trauma/. Communities can ensure that public and private agencies have the tools-such as assessments, evidence-informed interventions, and properly trained staff-to provide children and their families with timely, appropriate care to prevent child maltreatment and alleviate its effects. 
Communities can also promote a variety of protective factors for children. Protective factors are conditions or attributes of individuals, families, communities, or society that promote well-being and reduce the risk for negative outcomes, including the long-term consequences discussed in this factsheet (Child Welfare Information Gateway, 2015). They can "buffer" the effects of maltreatment. (See figure 2 for an illustration of the relationship between risk and protective factors.) Research shows the following are protective factors for victims of child maltreatment (Child Welfare Information Gateway, 2015):

- Individual level

- Sense of purpose

- Agency (self-efficacy)

- Self-regulation skills

- Relational skills

- Problem-solving skills

- Involvement in positive activities

- Relationship level

- Parenting competencies

- Positive peers

- Parent or caregiver well-being

- Community level

- Positive school environment

- Stable living situation

- Positive community environment

For more information, visit Information Gateway's Preventing Child Abuse \& Neglect (https://www. childwelfare.gov/topics/preventing/) and Responding to Child Abuse \& Neglect (https://www.childwelfare.gov/ topics/responding/) web sections.
Figure 2. Risk and Protective Factors

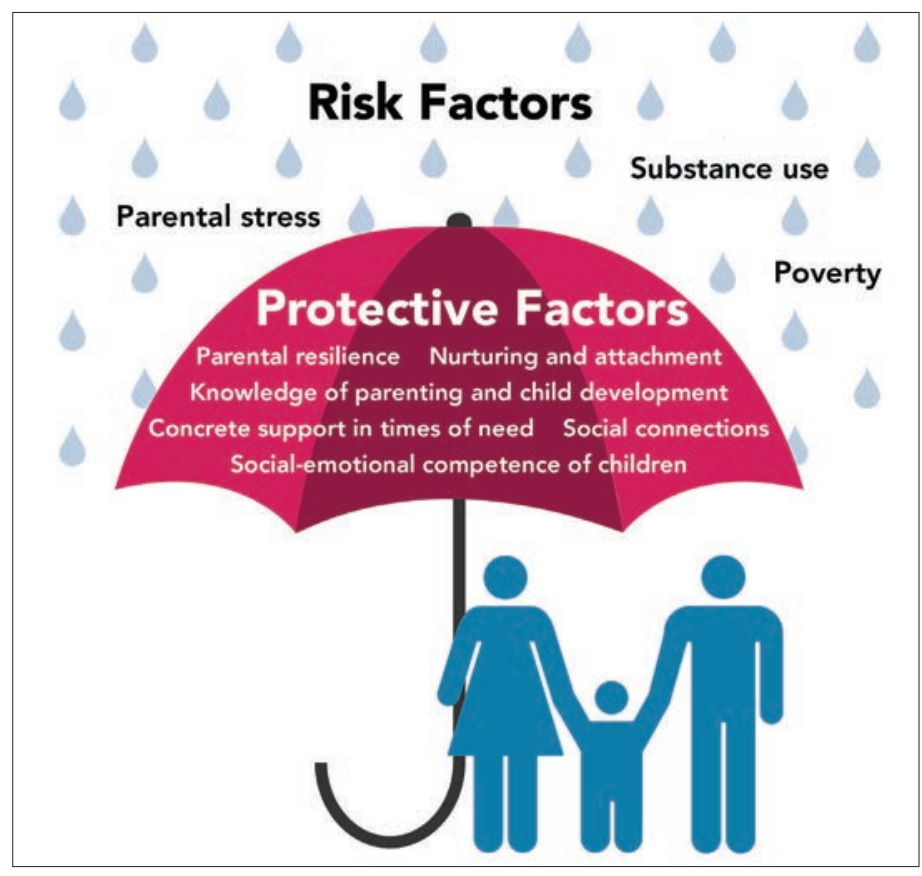

\section{Conclusion}

Child abuse and neglect can have devastating and long-lasting effects on a child and can result in detrimental societal impacts, including high costs for services and increased involvement in the juvenile and criminal justice systems. However, communities can act to stem the effects of maltreatment and even prevent it. Evidence-based services and supports can promote protective factors that mitigate the effects of maltreatment as well as provide families and communities with the tools to stop maltreatment before it occurs. Child welfare agencies can work with families and communities to spearhead initiatives that build upon strengths and address needs. 


\section{References}

Afifi, T. O., MacMillan, H. L., Boyle, M., Cheung, K., Taillieu, T., Turner, S., \& Sareen, J. (2016). Child abuse and physical health in adulthood. Health Reports, 27, 10-18.

Bick, J., \& Nelson, C. A. (2016). Early adverse experiences and the developing brain. Neuropsychopharmacology, 41, 177-196. Retrieved from https://www.nature.com/articles/ npp2015252. doi: 10.1038/npp.2015.252

Child Welfare Information Gateway. (2015). Promoting protective factors for victims of child abuse and neglect: $A$ guide for practitioners. Retrieved from https://www. childwelfare.gov/pubs/factsheets/victimscan/

Child Welfare Information Gateway. (2018). Cycle of abuse. Retrieved from https://www.childwelfare.gov/topics/can/ impact/long-term-consequences-of-child-abuse-andneglect/abuse/

Choi, N. G., DiNitto, D. M., Marti, C. N., \& Choi, B. Y. (2017). Association of adverse childhood experiences with lifetime mental and substance use disorders among men and women aged $50+$ years. International Psychogeriatrics, 29, 359-372. doi:10.1017/ S1041610216001800

Choi, N. G., DiNitto, D. M., Marti, C. N., \& Segal, S. P. (2017). Adverse childhood experiences and suicide attempts among those with mental and substance use disorders. Child Abuse \& Neglect, 69, 252-262. doi: 10.1016/j.chiabu.2017.04.024

Cicchetti, D., Hetzel, S., Rogosch, F. A., Handley, E. D., \& Toth, S. L. (2016). An investigation of child maltreatment and epigenetic mechanisms of mental and physical health risk. Development and Psychopathology, 28, 1305-1317. doi: $10.1017 /$ S0954579416000869

Doyle, C., \& Cicchetti, D. (2017). From the cradle to the grave: The effect of adverse caregiving environments on attachment and relationships throughout the lifespan. Clinical Psychology: Science and Practice, 24(2), 203-217. Doi: 10.1111/cpsp.12192
Fuller-Thomson, E., Baird, S. L., Dhrodia, R., Brennenstuhl, S. (2016). The association between adverse childhood experiences (ACEs) and suicide attempts in a populationbased study. Child: Care, Health and Development, 42, 725-734. Doi: 10.1111/cch.12351

Herrenkohl, T. I., Jung, H., Lee, J. O., \& Kim, M.-H. (2017). Effects of child maltreatment, cumulative victimization experiences, and proximal life stress on adult crime and antisocial behavior. Retrieved from https://www.ncjrs.gov/ pdffiles1/nij/grants/250506.pdf

Kavanaugh, B.C., Dupont-Frechette, J. A., Jerskey, B.A., \& Holler, K. A. (2016). Neurocognitive deficits in children and adolescents following maltreatment:

Neurodevelopmental consequences and neuropsychological implications of traumatic stress. Applied Neuropsychology: Child, 6, 64-78. Doi: 10.1080/21622965.2015.1079712

LeTendre, M. L., \& Reed, M. B. (2017). The effect of adverse childhood experience on clinical diagnosis of a substance use disorder: Results of a nationally representative study. Substance Use \& Misuse, 52, 689 697. doi: 10.1080/10826084.2016.1253746

Monnat, S. M., \& Chandler, R. F. (2015). Long-term physical health consequences of adverse childhood experiences. The Sociological Quarterly, 56, 723-752. doi: 10.1111/ tsq.12107

National Scientific Council on the Developing Child. (2010). Early experiences can alter gene expression and affect long-term development (Working paper 10). Retrieved from http://developingchild.harvard.edu/resources/ reports_and_working_papers/working_papers/wp10/

National Scientific Council on the Developing Child. (2014). Excessive stress disrupts the architecture of the developing brain (Working paper 3). Retrieved from https://developingchild.harvard.edu/resources/wp3/

Peterson, C., Florence, C., \& Klevens, J. (2018). The economic burden of child maltreatment in the United States, 2015. Child Abuse \& Neglect, 86, 178-183. doi: 10.1016/j.chiabu.2018.09.018 
Rosen, A. L., Handley, E. D., Cicchetti, D., \& Rogosch, F. C. (2018). The impact of patterns of trauma exposure among low income children with and without histories of child maltreatment. Child Abuse \& Neglect, 80, 301-311. doi: 10.1016/j.chiabu.2018.04.005

Sacks, V., \& Murphey, D. (2018). The prevalence of adverse childhood experiences, nationally, by state, and by race/ ethnicity. Retrieved from https://www.childtrends.org/ publications/prevalence-adverse-childhood-experiencesnationally-state-race-ethnicity

Sege, R. D.; Amaya-Jackson, L.; American Academy of Pediatrics Committee on Child Abuse and Neglect, Council on Foster Care, Adoption, and Kinship Care; American Academy of Child and Adolescent Psychiatry Committee on Child Maltreatment and Violence; \& National Center for Child Traumatic Stress. (2017). Clinical considerations related to the behavioral manifestations of child maltreatment. Pediatrics, 139(4). Retrieved from http://pediatrics.aappublications.org/content/pediatrics/ early/2017/03/16/peds.2017-0100.full.pdf

Thompson, R., Lewis, T., Neilson, E. C., English, D. J., Litrownik, A. J., Margolis, B. . . Dubowitz, H. (2017). Child maltreatment and risky sexual behavior. Child Maltreatment, 22, 69-78. doi: 10.1177/1077559516674595

U.S. Department of Health and Human Services, Administration for Children and Families. (2017). Toxic stress. Retrieved from https://www.acf.hhs.gov/traumatoolkit/toxic-stress.

U.S. Department of Health and Human Services, Administration for Children and Families, Children's Bureau. (2017). The AFCARS report: Preliminary FY 2016 estimates as of Oct 20, 2017 (Number 24). Retrieved from https://www.acf.hhs.gov/cb/resource/afcars-report-24
U.S. Department of Health and Human Services, Centers for Disease Control and Prevention, National Center for Injury Prevention and Control, Division of Violence Prevention. (2014). Essentials for childhood: Steps to create safe, stable, nurturing relationships and environments. Retrieved from https://www.cdc.gov/violenceprevention/ pdf/essentials_for_childhood_framework.pdf

U.S. Department of Justice, Office of Justice Programs, National Institute of Justice. (2017). Pathways between child maltreatment and adult criminal involvement. October 12, 2017. Retrieved from https://nij.gov/topics/ crime/children-exposed-to-violence/Pages/pathwaysbetween-child-maltreatment-and-adult-criminalinvolvement.aspx

Widom, C. S., Czaja, S. J., Bentley, T., \& Johnson, M. S. (2012). A prospective investigation of physical health outcomes in abused and neglected children: New findings from a 30-year follow up. American Journal of Public Health, 102, 1135-1144. doi: 10.2105/

AJPH.2011.300636

Williams, L. M., Debattista, C., Duchemin, A. M., Schatzberg, A. F., \& Nemeroff, C. B. (2016). Childhood trauma predicts antidepressant response in adults with major depression: data from the randomized international study to predict optimized treatment for depression. Translational Psychiatry, 6, e799. doi: 10.1038/tp.2016.61

Yang, M., Font, S. A., Ketchum, M., \& Kim, Y. K. (2018). Intergenerational transmission of child abuse and neglect: Effects of maltreatment type and depressive symptoms. Children and Youth Services Review, 91, 364-371. doi: 10.1016/j.childyouth.2018.06.036

\section{Suggested Citation:}

Child Welfare Information Gateway. (2019). Long-term consequences of child abuse and neglect. Washington, DC: U.S. Department of Health and Human Services, Administration for Children and Families, Children's Bureau.

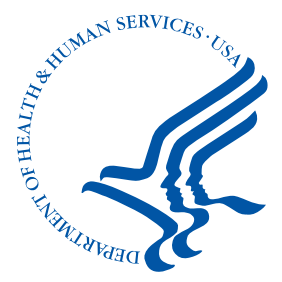

U.S. Department of Health and Human Services Administration for Children and Families Administration on Children, Youth and Families Children's Bureau
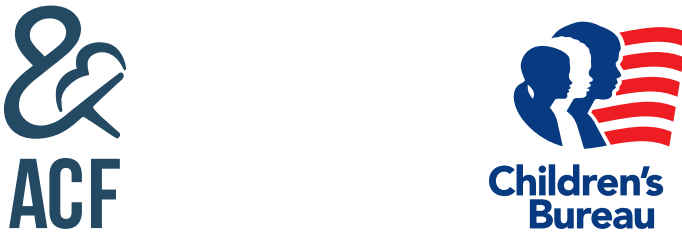